\title{
More sinning than sinned against
}

\author{
Fiona Godlee editor in chief
}

The BMJ

\begin{abstract}
Among the statistical sins of England's health secretary, Jeremy Hunt, summarised and rebutted this week by David Craven (doi:10.1136/bmj.h6358), we might soon have to include an assertion by Hunt that patients will die if junior doctors strike. But an Analysis article this week indicates otherwise. David Metcalfe and colleagues have taken a systematic look at studies reporting mortality data from doctors strikes' around the world (doi:10.1136/bmj.h6231). Of the six studies from developed countries, none showed an increase in mortality. Indeed, in two cases mortality fell during strikes. The authors conclude that, given this evidence, and provided that emergency care is available, doctors' strikes do not put the safety of patients at risk.
\end{abstract}

This is reassuring, as are assurances from the BMA and the General Medical Council that (and who could doubt it) doctors will respond in the event of a major incident (doi:10.1136/bmj. h6322). But a strike is still something most doctors would greatly prefer to avoid. "We don't want to strike," writes Roshana Medhian in BMJ Careers, "but for the good of our patients, colleagues, and the NHS we may have to" (http:// careers.bmj.com/careers/advice/Junior_doctors\%E2\%80\%99_ winter_of_discontent\%3A_public_needs_to_know_why_ striking_is_necessary).

Our editorialist David Hunter recognises this wider context to the current dispute (doi:10.1136/bmj.h6317). Beyond the juniors' concerns about longer hours and less pay sits an established and growing erosion of trust between NHS staff and politicians. The current funding crisis, only slightly abated by the latest spending announcements (doi:10.1136/bmj.h6356), has hit while NHS staff are still struggling with the consequences of the coalition's unnecessary, expensive, and damaging Health and Social Care Act. The act and the increasingly unrealistic demands for efficiency fuel fears that the government's real agenda is to dismantle the NHS.

Whether Hunt wants a strike is hard to tell. He certainly seems to have set his face against the profession, repeatedly portraying doctors as the only obstacle to his dream of a fully functional seven day service. A paper this week will add fuel to his fire, but I and David Craven advise caution. The study confirms a "weekend effect" in obstetrics, with a slight but statistically significant increased risk of death in babies born at weekends (doi:10.1136/bmj.h5774). But, as with The BMJ's recent paper on the weekend effect in hospitals (doi:10.1136/bmj.h4596), this study does not attribute excess deaths to lower staffing at weekends. Only one outcome was associated with the level of consultant staffing. And no data were available to assess other crucial resourcing, such as numbers of midwives on duty.

With consultants and GPs standing by their junior colleagues, Margaret McCartney writes that Hunt's biggest success as health secretary has been "to unite the medical profession-against him" (doi:10.1136/bmj.h6279). Rather than misusing yet more statistics, Hunt should take this brief opportunity to regain the profession's goodwill, by seeking independent arbitration and averting the strike.

Cite this as: BMJ 2015;351:h6369

๑ BMJ Publishing Group Ltd 2015 